\title{
LA INCIDENCIA DE LA FALTA DE APORTACIÓN DOCUMENTAL EN LA CONCESIÓN DE LA NACIONALIDAD POR RESIDENCIA: EL CASO MESSAOUD
}

\author{
THE INCIDENCE OF THE LACK OF DOCUMENTARY \\ CONTRIBUTION IN THE CONCESSION OF NATIONALITY \\ BY RESIDENCE: THE MESSAOUD CASE
}

\author{
Esther Gómez CAMPelo \\ Profesora Titular de Derecho Internacional Privado \\ Universidad de Burgos
}

Recibido: 12.11.2020 / Aceptado: 27.11.2020

DOI: https://doi.org/10.20318/cdt.2021.5998

\begin{abstract}
Resumen: Se analiza la Sentencia del Tribunal Supremo que reconoce el derecho a la nacionalidad española por residencia, tras la valoración positiva de la buena conducta cívica pese a carecer de la documentación requerida para su acreditación. Es la ponderación global de las diversas circunstancias personales que concurren la que ha de hacer concebir a la autoridad competente una convicción fundada acerca del requisito y no una rígida apreciación de las exigencias reglamentarias sobre la documentación a presentar. También se analiza la interrelación entre la buena conducta cívica y la carencia de antecedentes penales $\mathrm{y} / \mathrm{o}$ policiales.

Palabras clave: nacionalidad, documentación, buena conducta cívica, certificado de antecedentes penales.

Abstract: The judgment of the Supreme Court that recognizes the right to Spanish nationality by residence is analyzed, after the positive assessment of good civic conduct despite lacking the documentation required for its accreditation. It is the global weighting of the various personal circumstances that concur that must make the competent authority conceive a well-founded conviction about the requirement and not a rigid assessment of the regulatory requirements on the documentation to be presented. The interrelation between good civic conduct and the lack of criminal and/or police records is also analyzed.
\end{abstract}

Keywords: nationality, documentation, good civic conduct, criminal record certificate

Sumario: I. Antecedentes de la Sentencia del Tribunal Supremo, Sala de lo Contencioso Administrativo, Sección Quinta, de 9 de julio de 2020. II. Análisis de la Sentencia. 1. Exigencia de requisitos documentales. A) Breve alusión al marco regulador. B) La dificultad en la obtención de documentación. 2. La concreción de la buena conducta cívica y su acreditación. 3. El papel de los antecedentes penales y policiales. III. Conclusiones.

I. Antecedentes de la Sentencia del Tribunal Supremo, Sala de lo Contencioso Administrativo, Sección Quinta, de 9 de julio de 2020

1. El 7 junio de 1998 un helicóptero de las FFAA argelinas aterrizó en una playa ibicenca. El desembarco del teniente del ejército argelino A. Messaoud y su prevista deserción aprovechando unas 
maniobras militares en su Base Aérea, fue objeto de atención por los medios locales y nacionales. Ahora, 22 años después, sigue siendo noticia ${ }^{1}$.

La solicitud de concesión de la nacionalidad española por residencia chocó con dos Resoluciones desestimatorias de la DGRN en las que se aludía a la falta de documentación exigida para poder tramitar el expediente, en concreto, el certificado de nacimiento y de antecedentes penales de su país de origen con la preceptiva legalización, así como el pasaporte acreditativo de su nacionalidad. Contra dichas Resoluciones, se formuló por el recurrente recurso contencioso-administrativo 855/2017, tramitado por la Sección Séptima de la Sala de lo Contencioso-Administrativo de la Audiencia Nacional que, el 27 de junio de 2019, dictó sentencia también desestimatoria, abundando en los argumentos mencionados.

2. El núcleo de la cuestión consiste en establecer si puede justificarse una denegación de concesión de la nacionalidad española por el hecho de que el solicitante no haya aportado algunos de los documentos que se le requieren, y si tal documentación es imprescindible para justificar las condiciones que nuestra normativa exige. El estudio de la resolución del TS² nos permitirá profundizar en el razonamiento casacional, en sus antecedentes y en la doctrina que, de forma persistente parece estarse consolidando.

\section{Análisis de la Sentencia}

\section{Exigencia de requisitos documentales}

\section{A) Breve alusión al marco regulador}

3. Las solicitudes de adquisición de la nacionalidad española por parte de extranjeros con residencia en nuestro país han experimentado un enorme crecimiento en los últimos años; ello ha motivado que la DGRN haya querido no sólo agilizar los procedimientos, sino dotarles de mayor seguridad para los interesados y una mayor eficacia en la gestión. En tal sentido se manifestó la Instrucción de 26 de julio de 2007 de la DGRN, sobre tramitación de las solicitudes de adquisición de la nacionalidad española por residencia ${ }^{3}$. Y, además, dictó unas directrices en uso de las facultades que le atribuyen los arts. 9 de la LRC y 41 del RRC que, para lo que ahora nos interesa, se aluden en la Primera. Ordenación y foliación del expediente ${ }^{4}$.

Un lustro después, la Instrucción de 2 de octubre de 2012, de la DGRN, sobre determinados aspectos del Plan intensivo de tramitación de los expedientes de adquisición de la nacionalidad española por residencia ${ }^{5}$, abunda en la necesidad de examinar con rigor la documentación que ha de aportar el interesado, que "comprenderá el de la suficiencia y validez de los documentos para el fin pretendido". Para concretar aún más esta exigencia documental, la Instrucción remite a su Anexo I, donde se apunta que el "expediente de nacionalidad por residencia, en su fase registral, se compondrá exclusivamente de los documentos que se especifican" y que, respecto a nuestro estudio serían la certificación de nacimiento del interesado, debidamente traducida y legalizada y el certificado de antecedentes penales o consular de conducta de su país de origen, traducido y legalizado, de acuerdo con los Convenios internacionales existentes ${ }^{6}$.

${ }^{1}$ La historia de aquel aterrizaje y lo que vino después se ha narrado por M. VEGA Alocén en el libro La huida del teniente Alili Massaoud, Edit. Círculo Rojo, 2015.

${ }^{2}$ STS de 9 de julio 2020. ECLI:ES:TS: 2020:2241.

${ }^{3}$ BOE núm. 189 de 8 de agosto de 2007.

${ }^{4}$ El expediente de nacionalidad por residencia, en su fase registral, se conformará con los documentos o, en su caso, copia cotejada de los mismos, que se indican a continuación (...)

- Certificado de nacimiento del interesado.

- Certificado expedido de antecedentes penales del país de origen, o consular de buena conducta.

- Otros documentos que quiera aportar el interesado, o, que sean requeridos por el Encargado del Registro Civil y que guarden relación con el objeto del expediente.

${ }^{5}$ BOE núm. 247, de 13 de octubre de 2012.

${ }^{6}$ Web del Ministerio de Justicia https://www.mjusticia.gob.es/cs/Satellite/Portal/es/ciudadanos/tramites-gestiones-personales/nacionalidad-residencia; (Fecha de consulta, 4 de noviembre de 2020). 
4. Así pues, teniendo presentes ambas Instrucciones de la DGRN, y sin olvidar la normativa aplicable al supuesto -los arts. 22,4 CC y $220^{7}$ y 221 RRC-, es importante precisar qué trascendencia real tiene sobre la solicitud la ausencia de documentos y si, en tal caso, sería posible mantener la tramitación del expediente. Sobre este particular ya se han pronunciado diferentes resoluciones de nuestros Tribunales que seguidamente pasaremos a referir y que no obstante su profusión, no mantienen un criterio uniforme.

\section{B) La dificultad en la obtención de documentación}

5. Las resoluciones administrativas que denegaron a Messaoud la concesión de nacionalidad ante la falta de aportación de algunos documentos, no tuvieron en cuenta las dificultades del solicitante para su obtención ni la posibilidad de analizar otros elementos en presencia para llegar a una conclusión que le favoreciera en su pretensión ${ }^{8}$.

La SAN ${ }^{9}$ no dudó en admitir tales dificultades en recabar la documentación exigida en su país de origen, Argelia, debido a la situación personal del solicitante (deserción de las FFAA de su país); pero justificó sus argumentos no sólo por el carácter insoslayable de los documentos a presentar, sino en que aquel ni siquiera argumentó tales impedimentos personales en su obtención, lo que hubiera activado la colaboración de la Administración, promoviendo la solicitud de los medios de prueba.

6. La ausencia de cumplimiento de los requisitos formales según las Instrucciones de la DGRN antes referidas, que indican expresa y detalladamente los documentos que el sujeto debe aportar en su solicitud ${ }^{10}$, supusieron la denegación por Resolución del Director General de los Registros y del Notariado (17 de mayo de 2013) y de la desestimación del recurso de reposición presentado ante el mismo órgano (16 de febrero de 2015), así como la citada sentencia de la Audiencia Nacional (27 de junio de 2019) en resolución del recurso contencioso-administrativo interpuesto por el solicitante.

7. En todos los casos fue la falta de documentación el elemento clave para las resoluciones denegatorias, ofreciendo un tratamiento formalista estricto y una interpretación rigorista del art. $22 \mathrm{CC}$ y los arts. del RRC, planteamientos que, como veremos, fueron puestos en cuestión por nuestro Tribunal Supremo mucho antes de la resolución que ahora se analiza ${ }^{11}$, valorando que en el conjunto del expediente existen datos suficientes que permiten a la autoridad competente verificar la ausencia de antecedentes penales, y que el certificado de nacimiento legalizado -que tampoco fue presentado, aun cuando constaba tal fecha en su inscripción y sucesivas renovaciones en el Registro de Extranjeros- puede ser "sustituido" por la documentación que obra en el expediente por el que al solicitante se le concedió y prorrogó la autorización de residencia en España, a tenor de su completa identificación por parte de la administración española.

\footnotetext{
${ }^{7}$ Art. 220 RRC:

En la solicitud de (...) concesión de la nacionalidad por residencia, se indicará especialmente:

$1 .{ }^{\circ}$ Menciones de identidad, lugar y fecha de nacimiento del solicitante (...)

3. ${ }^{\circ}$ Si está procesado o tiene antecedentes penales. Si ha cumplido servicio militar o prestación equivalente, exigidos por las leyes de su país, o situación al respecto (...).

${ }^{8}$ M. Álvarez Rodríguez, "Inmigrantes e hijos de inmigrantes nacidos en España: vías de acceso a la nacionalidad española”, Revista del Ministerio de Trabajo e Inmigración, no 90, 2010, p. 109.

${ }^{9}$ ECLI:ES:AN: 2019:2684.

${ }^{10} \mathrm{El}$ art. 7 de la Orden JUS/1625/2016, de 30 de septiembre, sobre la tramitación de los procedimientos de concesión de la nacionalidad española por residencia (BOE núm. 246, 11 octubre 2016) detalla cómo debe ser la instrucción del procedimiento sobre la adquisición de la nacionalidad española por residencia.

${ }^{11}$ La STS (Sec. 6a) de 30 de septiembre 2008, indica que la aportación del certificado de antecedentes penales del país de origen no es un requisito insoslayable. La Administración española puede prescindir de él cuando conste la existencia de dificultades notables -no imputables a desidia del interesado-, para la obtención de dicho certificado.
} 


\section{La concreción de la buena conducta cívica y su acreditación}

8. Cuando el art. $22,4 \mathrm{CC}$ hace constar que "el interesado deberá justificar en el expediente regulado por la legislación del Registro Civil buena conducta cívica..." está poniendo de relieve que, junto a los requisitos formales o documentales existen otros, sustanciales o materiales (de carácter positivo ambos, buena conducta cívica e integración en la sociedad española ${ }^{12}$. Sin duda ha sido la Jurisprudencia la que ha ido precisando y adaptando los límites del concepto que nos ocupa hasta fijar las bases sobre las que hoy se asienta.

9. No basta, pues, con la residencia en España (legal, continuada e inmediatamente anterior a la solicitud) sino un grado aceptable de adaptación "a la cultura y estilo de vida españoles"13, esto es, la armonización del régimen de vida del solicitante a los principios y valores demostrando suficiente grado de integración en la sociedad española y, además, un comportamiento acreditado a través de una conducta cívica irreprochable en el marco de nuestro ordenamiento. El tránsito de la mera residencia en España a la obtención de la nacionalidad exige una actitud en el solicitante adaptada a la que se requiere a los ciudadanos españoles ${ }^{14}$.

10. La doctrina de los tribunales parece tener tres formas de encarar este requisito:

1. Exigir la falta de antecedentes penales y/o policiales, así como una buena conducta ciudadana, de forma acumulada.

2. Entender que la ausencia de antecedentes no garantiza, per se, el cumplimiento del requisito si el civismo del solicitante se ha comprobado inexistente o dudoso.

3. Valorar que incluso con antecedentes, la buena conducta cívica por sí misma puede ser suficiente. De la misma forma, no cabría denegar la nacionalidad -pues ello no prueba una mala conducta- por la única circunstancia de que se presenten informes policiales negativos.

11. El fundamento de nuestra Sentencia basa sus argumentaciones en el estudio -en absoluto novedoso- del concepto indeterminado de la "buena conducta cívica", su perfil y contenidos, así como de aquellos aspectos que le son colaterales y, en tal sentido, accesorios o incluso irrelevantes.

${ }^{12}$ J. L. ReQUero IBÁÑEz, “Adquisición de la nacionalidad por residencia. Análisis jurisprudencial del art. 22,4 del Código Civil: la buena conducta cívica y el suficiente grado de integración”, en Revista Galega de Administración Pública n 32, 2002.

H. AL RACHED, "Adquisición de la nacionalidad española y matrimonio poligámico: aspectos críticos y prácticos", en Cuadernos de Derecho Transnacional (octubre 2020), Vol. 12, nº 2, p. 849.

M. Blanco ToRiBio, "La importancia del requisito de la buena conducta cívica en la adquisición de la nacionalidad española", en Revista Jurídica de la Comunidad de Madrid, n 15, 1-I-2003.

${ }^{13}$ SAN, Sala de lo Contencioso, Sección 1a, 8/2018, de 4 de enero 2018. ECLI: ES:AN: 2018:8.

J. CArrascosa GonzÁlez, “Adquisición de la nacionalidad española por residencia en España art.22”, en M. Pasquau Liaño., Jurisprudencia Civil Comentada: Código Civil, Comares, Granada, Tomo I, 2000.

M. GuzmÁn Peces, "La integración en la adquisición de la nacionalidad española por residencia. Algunas reflexiones en torno a la apreciación de las cuestiones religiosas por parte de los tribunales", en Anuario de Derecho Eclesiástico del Estado, vol. XXX (2014).

${ }^{14}$ Como recuerda la STS de 22 de noviembre 2001 (Rec. casación núm. 7947/1997) y apuntala la STS de 28 septiembre 2005 (Sec. $6^{a}$ ), Rec. 4919/2001 (Fundamento Jurídico $3^{\circ}$ ): “ (...) al ser la nacionalidad española el sustrato y fundamento necesario para el ejercicio pleno de los derechos políticos, es dable exigir al sujeto solicitante, a consecuencia del "plus" que contiene el acto de su otorgamiento enmarcable dentro de los "actos favorables al administrado", un comportamiento o conducta que ni siquiera por vía indiciaria pudiera cuestionar el concepto de bondad que el precepto salvaguarda, como exigencia especifica determinante de la concesión de la nacionalidad española. "No está de más recordar también que la diferencia de naturaleza entre la llamada "concesión de la nacionalidad" y la "concesión de servicio público" está claramente establecida en la doctrina administrativa desde hace años, la cual distingue la concesión de servicio público stricto sensu de las concesiones de status, entre ellas la concesión de la ciudadanía, advirtiendo que la palabra "concesión" se utiliza en estos otros casos en un sentido puramente lexicológico, como sinónima de otorgar, conferir o donar". En idéntico sentido, la STS de 15 de diciembre 2004, Rec. 1876/2001.

M ${ }^{a}$ E. Cobas Cobiella, "Una mirada a los requisitos e la obtención de la nacionalidad española por residencia”, en Barataria, Revista Castellano-Manchega de Ciencias Sociales, $\mathrm{n}^{\circ}$ 17, 2014. 
12. La interdicción de la arbitrariedad de los poderes públicos y la seguridad jurídica ante la falta de concreción "ex lege" exige abordar casuísticamente las solicitudes bajo el principio, entre otros, de igualdad ante la ley ${ }^{15}$. Tampoco parece admisible la simple comprobación mecánica de los requisitos aportados, puesto que la capacidad decisoria que se le concede a la Administración en este ámbito ha de vincularse, como tendremos ocasión de apreciar, a la justa solución del caso y la ponderación de los diferentes elementos en presencia ${ }^{16}$.

Con todo, parece evidente pensar que, ante un concepto jurídico no legislado, que se mantuvo sin alterar en la Ley 36/2002, de modificación del CC en materia de nacionalidad ${ }^{17}$, la autoridad competente ha de buscar elementos objetivos en los que apoyar sus argumentaciones, favorables o contrarias a la concesión de la nacionalidad. Y, ciertamente, una forma de valorar la buena conducta cívica ha sido -como veremos- el recurso al certificado de ausencia de antecedentes penales.

13. La adecuada valoración de la conducta es ajena al solicitante de la nacionalidad, pues depende del tribunal que conozca el verificar las pruebas aportadas y apreciar las circunstancias que concurran en el caso concreto.

14. Respecto a quién ha de acreditar buena conducta cívica más allá de la prueba documental, el art. 221 RRC exige al peticionario probar, entre otros extremos, su identidad, lugar y fecha de nacimiento, así como si está procesado o tiene antecedentes penales ${ }^{18}$. Así lo expresa el art. 22,4 CC cuando emplea los términos "deberá justificar", lo que conlleva una coherencia entre la documentación presentada al expediente, sus propias alegaciones y los datos que obren en poder de las instancias oficiales correspondientes. Lo que no parece razonable es que al solicitante se le exija demostrar que ha ostentado un comportamiento social ejemplar e intachable a lo largo de su vida, sino que lleva una existencia correcta desde el punto de vista de un "estándar medio de conducta"19. Y es que, en la medida en que "la buena

${ }^{15}$ STS de 12 de mayo 2005, Sala de lo Contencioso-Administrativo, sección $6^{\text {a }}$ (RJ 2005/4226).

R. VIÑAS Farré, "Evolución del Derecho de nacionalidad en España: continuidad y cambios más importantes", en https:// www.ehu.eus/documents/10067636/10761851/2009-Ramon-Vinas-Farre.pdf/4895d2d7-7660-6e09-673f-00fc1c81fe2b (Fecha de consulta, 1 de noviembre de 2020).

${ }^{16}$ G. Pinyol i JimÉnez; E. SÁnchez MontiJano , "La naturalización en España. Una política de claroscuros”, en Anuario CIDOB de la inmigración, 2014. https://www.raco.cat/index.php/AnuarioCIDOBInmigracion/article/view/287328 (Fecha de consulta, 30 de octubre 2020).

En la SAN 1775/2019. ECLI: ES:AN: 2019:1775, se aborda la discrecionalidad "En esta materia resulta excluida la discrecionalidad de la Administración, porque la inclusión de un concepto jurídico indeterminado en la norma a aplicar no significa, sin más, que se haya otorgado capacidad a la Administración para decidir con libertad y renunciar a la solución justa del caso, sino que viene obligada a la única decisión correcta a la vista de los hechos acreditados. Sin duda, el reconocimiento de la nacionalidad española por residencia no constituye el ejercicio de una potestad discrecional, encontrándonos, por el contrario, ante una potestad reglada, pues es un deber cuando concurren los requisitos legalmente previstos. De ahi que su naturaleza jurídica difiera de la potestad de concesión de nacionalidad por carta de naturaleza, pues mientras ésta constituye un genuino derecho de gracia, en que el requisito de la solicitud tiene el significado de ocasión o motivo pero no causa jurídica de la misma, la adquisición por residencia no puede concederse o denegarse sino cuando concurran las circunstancias legalmente previstas, de manera que no se trata de una concesión "stricto sensu" sino de un reconocimiento por concurrir al efecto los requisitos exigibles. Asi lo hemos declarado, entre otras, en sentencias de 9 de octubre de 2015, Rec. 25/2015, y 16 de octubre de 2015, Rec. 15/2015".

${ }^{17}$ BOE núm. 242, de 9 de octubre de 2002.

${ }^{18}$ Ahora bien, el art. 221 RRC configura la aportación de este requisito "si es posible".

${ }^{19}$ E. Rubio Torrano, "La buena conducta cívica en la adquisición de la nacionalidad española por residencia", en Aranzadi Civil $\mathrm{n}^{\mathrm{o}} 1,2004$.

A. Rubio Castro; M. Moya Escudero, "Nacionalidad y ciudadanía: una relación a debate", en Anales de la Cátedra Francisco Suárez,37 (2003).

La SAN 1231/2020, Sec. $3^{\text {a }}$, de 12 de junio 2020. ECLI: ES:AN: 2020:1231, respecto a la dificultad para precisar qué debe entenderse por buena conducta cívica, remite a la STS, Sec. $6^{\text {a }}$, de 12 noviembre 2002 (Rec. Casación núm. 4857/1998) que señala: “(...) Y por eso importa dejar claro que este sintagma que emplea el artículo 22.4 del Código Civil remite a un estándar medio de conducta capaz de ser asumido por cualquier cultura y por cualquier individuo. Un estándar que vale para todos y vale para cada uno. En el bien entendido que no se trata de imponer un modo de vida uniforme en la comunidad nacional, ni de que quien utiliza esta vía de adquisición de la nacionalidad tenga que demostrar que durante toda su vida haya observado una conducta intachable, sino de proclamar que, siendo cada sujeto humano libre para organizar su vida como le plazca-la vida se nos da, pero no se nos da hecha: tenemos que hacérnosla quienes, no siendo españoles, deseen obtener la nacionalidad española, han de haber llevado y seguir llevando una vida ajustada a ese estándar medio de conducta al que acabamos de referirnos". 
conducta civica no se presume"20, es al solicitante a quien corresponde la carga de probarla, así como su suficiente grado de integración en la sociedad española. Para ello, es importante que aporte datos que indiquen de forma inequívoca su buena conducta cívica ${ }^{21}$, lo que “... remite a un estándar medio de conducta capaz de ser asumido por cualquier cultura y por cualquier individuo"22. En el caso objeto de análisis, pudo conocerse que, tras fijar su residencia en Ibiza, y sin existir constancia del abandono de la isla, el sr. Messaoud solicitó y obtuvo permiso de residencia temporal desde 1999 -permanente desde 2004- siendo periódicamente renovado hasta 2018. Consta documentalmente su empadronamiento y trabajo ininterrumpido desde 1999, con cotizaciones a la Seguridad Social durante más de 16 años (según acredita su Informe de Vida Laboral).

15. En el RRC no se contienen reglas en relación con la justificación de la buena conducta cívica, por lo que puede ser acreditada por cualquier medio de prueba ${ }^{23}$, y las posibilidades son numerosas (informes policiales, autos de sobreseimiento recaídos en los procedimientos en los que se encontraba incurso el solicitante y, por supuesto, los certificados de cancelación de antecedentes penales). Todo ello, con la posibilidad de que el encargado del Registro proporcione audiencia al interesado, para conformar mejor su criterio, al permitirle, a través de una apreciación directa, verificar el requisito de una forma más ponderada ${ }^{24}$, aunque con las necesarias reservas acerca de tal valoración ${ }^{25}$.

16. De esta forma, pueden constatarse las dificultades con las que el juez se encuentra para determinar lo que, coyunturalmente, deba entenderse por buena conducta cívica porque, pese a citarse la expresión "estándar medio de conducta capaz de ser asumido por cualquier cultura y por cualquier individuo" en numerosas resoluciones judiciales, también se nos dice que "no podemos llamar buena conducta civica a cualquier cosa", lo que abunda en la necesidad de una interpretación actual (en atención a las circunstancias del momento), coherente (con un nivel medio de exigencia), respetuosa (no se trata de imponer un modo de vida uniforme para todo el país), armonizada ${ }^{26}$ y de conjunto, es

${ }^{20}$ STS, Sec. 6 a de 16 de junio 2009, Rec. 2915/2005 (RJ 2009/6596)

${ }^{21}$ SAN de 12 de marzo 2013, Sec. $3^{\text {a }}$, Rec. 280/2011.

${ }^{22}$ SAN de 26 de diciembre 2014, Sec. $3^{\text {a }}$, -Fundamento Jurídico $3^{\circ}$ - 5056/2014 - ECLI: ES:AN: 2014:5056.

${ }^{23}$ SSAN, Sec.3 ${ }^{\text {a }}$, Rec. 1052/2019, de 29 de julio 2020; Rec. 12/2019, de 29 de julio 2020; Rec. 2042/2019, de 2 de julio 2020; Rec. 527/2018, de 18 de septiembre 2019; Rec. 317/2017, de 8 de abril 2019; Rec. 375/2017, de 6 de febrero 2019; Rec. $625 / 2017$, de 21 de febrero 2019, entre otras.

${ }^{24}$ SAN 885/2014, Sec. 3a. "Esta audiencia prevista en el marco del art. 221 del RRC expresa el juicio, especialmente cualificado, que se forma el Juez del Registro Civil mediante apreciación directa y personal y no precisa de la corroboración mediante la firma del examinado" (Fundamento Jurídico $4^{\circ}$ ). Y "En lo que aqui es relevante se hace preciso ponderar si la valoración efectuada por el Encargado del Registro Civil se revela como razonable y ponderada, sin perjuicio del valor privilegiado que ostenta la entrevista en orden a verificar el grado de adaptación a la cultura y estilo de vida español, en razón de la inmediación de la que goza el Encargado" (Fundamento Jurídico $6^{\mathrm{a}}$ )

25 “(...) aunque el informe del Encargado presenta singular relevancia en función de la inmediación de la que goza, no es vinculante ni siquiera cuando es favorable, y no es el único que la Dirección competente puede o debe recabar, al margen, claro está, de que la decisión sobre el otorgamiento de la nacionalidad corresponda al Ministro de Justicia (art. 21.2 Código Civil). En consecuencia, el hecho de que aquel informe sea favorable no acredita por sí mismo la concurrencia del requisito de la buena conducta, pudiéndose separar fundadamente del mismo tanto el ministro, como los Tribunales (en análogo sentido, STS de 2 de junio de1998, recurso 495/1994 y SAN de 9 de octubre de 2015, procedimiento ordinario 352/215)". Fundamento Jurídico $2^{\circ}$, SAN 772/2020, Sec. $6^{\text {a }}$, de 6 de junio 2020. ECLI: ES:AN: 2020:772.

26 “(...) Un estándar que vale para todos y vale para cada uno. En el bien entendido que no se trata de imponer un modo de vida uniforme en la comunidad nacional, ni de que quien utiliza esta vía de adquisición de la nacionalidad tenga que demostrar que durante toda su vida haya observado una conducta intachable, sino de proclamar que, siendo cada sujeto humano libre para organizar su vida como le plazca -la vida se nos da, pero no se nos da hecha: tenemos que hacérnosla-, quienes, no siendo españoles, deseen obtener la nacionalidad española, han de haber llevado y seguir llevando una vida ajustada a ese estándar medio de conducta al que acabamos de referirnos". Y también, “(...) en nuestra sentencia de 12 de noviembre del 2002 (recurso de casación 4857/1998) dijimos que «la realidad social (art. 3.1 del Código civil) a la que el intérprete ha de acudir para interpretar el ordenamiento jurídico es una realidad caleidoscópica cuyos elementos, que podrían tenerse por inmutables a primera vista, cambian de posición a medida que gira la rueda de la vida. Y es esta imagen la que permite entender por qué la escala de valores cambia según las convicciones sobre el mundo, la vida y el hombre que tienen las sucesivas generaciones sociológicas. Esto que decimos no es pura retórica sino algo perfectamente constatable en la jurisprudencia del Tribunal constitucional. Piénsese en lo sucedido con el derecho al honor y el de libertad de expresión: prevalencia, en una primera 
decir, verificando la trayectoria personal del solicitante sobre la base del mencionado estándar medio de conducta $^{27}$. Así pues, la valoración subjetiva del encargado de verificar el expediente adquiere un papel altamente significativo en el iter de la tramitación.

\section{Papel de los antecedentes penales y policiales}

17. Resulta evidente que una condena penal tiene suficiente relevancia como para condicionar la valoración de la buena conducta cívica del solicitante, aunque no suponga un automatismo. Incluso la presencia de conductas delictivas graves han de ser moduladas en su percepción por la autoridad competente ya que no todas ponen de relieve la misma ausencia de civismo ${ }^{28}$. En este contexto, la buena conducta cívica no ha de hacerse equivaler a la carencia de antecedentes penales ${ }^{29}$, porque independientemente de su cancelación -como sucede en la sentencia de referencia, con la acreditada cancelación de antecedentes policiales- son tan sólo un indicador -eso sí, cualificado- de la conducta del sujeto, pero no pueden, por sí solos, acarrear la denegación de la nacionalidad española ${ }^{30}$.

18. En cuanto a la trascendencia de los Informes policiales, el Tribunal Supremo ha reiterado que una infracción administrativa también puede ser indicativa de falta de buena conducta cívica ${ }^{31}$ pero añadiendo que los Informes negativos no conducen automáticamente a descartar la buena conducta; la doctrina jurisprudencial recogida en numerosas sentencias expone que la fuerza probatoria de un Informe policial ha de ponerse en contexto con otros hechos conocidos del sujeto y en relación con los demás medios de prueba ${ }^{32}$.

etapa del derecho al honor (STC de 19 de enero y 28 de octubre de 1988); equiparación, después, de uno y otro derecho, lo que implica tener que ponderar los intereses en juego (STC 104/1986, STC 159/1986); y, por último, prevalencia de las libertades de expresión e información (STC 165/1988, y STC 59/1989). El progresivo cambio de una estimativa de valores no puede ser más patente”. Así puede leerse en la STS de 15 de diciembre 2004, Rec. 1876/2001.

${ }^{27}$ STS, Sec. 6. ${ }^{\text {a }}$, de 12 noviembre 2002 (Rec. Casación núm. 4857/1998)

${ }^{28}$ SAN, Sec. $3^{\text {a }}, 5056 / 2014$, de 26 de diciembre 2014. ECLI: ES:AN: 2014:5056.

A. Ortega JimÉnez, “Antecedentes penales y acceso a la nacionalidad española”, en Actualidad Jurídica Aranzadi no 812, Pamplona 2011.

${ }^{29}$ En STS de 16 de marzo 1999, Sec. 6á, (RJ 1999\3044) podía leerse que en el supuesto de la concesión de nacionalidad por residencia, la exigencia de "justificar, en el expediente regulado por la legislación del Registro Civil, buena conducta cívica" (además de suficiente grado de integración en la sociedad española) (art. 22.4 Código Civil), constituye un requisito adicional sobre la mera observancia de una conducta de no trasgresión de las normas penales o administrativas sancionadoras, impuesto por el ordenamiento jurídico en razón del carácter excepcional que supone el reconocimiento de la nacionalidad por residencia y, por ende envuelve aspectos que trascienden los de orden penal y ha de ser valorada atendiendo a la conducta del solicitante durante un largo periodo de tiempo y permanencia en España y no puede identificarse sin más con la ausencia de antecedentes penales o policiales".

${ }^{30}$ Nada tiene que ver, como indica el Tribunal Supremo, el concepto jurídico indeterminado, buena conducta cívica, a que se refiere el art. 22,4 CC, con la carencia de antecedentes penales a que se refiere en último término la norma invocada, ya en la sentencia de 16 de marzo de 1999 se decía que en el supuesto de la concesión de nacionalidad por residencia, la exigencia de «justificar, en el expediente regulado por la legislación del Registro Civil, buena conducta cívica» (además de suficiente grado de integración en la sociedad española) ( art. 22.4 CC), constituye un requisito adicional sobre la mera observancia de una conducta de no trasgresión de las normas penales o administrativas sancionadoras, impuesto por el ordenamiento jurídico en razón del carácter excepcional que supone el reconocimiento de la nacionalidad por residencia y, por ende envuelve aspectos que trascienden los de orden penal y ha de ser valorada atendiendo a la conducta del solicitante durante un largo periodo de tiempo y permanencia en España y no puede identificarse sin más con la ausencia de antecedentes penales o policiales. De contrario los antecedentes policiales y penales, con independencia de su cancelación, son meramente un indicador cualificado de la conducta de un ciudadano, sin que puedan ser, por sí solos, un obstáculo para la concesión de la nacionalidad española (Sentencia TS de 5-11-2001 Rec. casación núm. 5912/1997). Así podemos leer en la SAN 1191/2020, de 10 de junio 2020, ya citada. También, en la STS de 5 de noviembre 2001, Rec. 5912/1997. Y en las SSTS de 12 de febrero 2010, Rec. 1076/2007; de 29 de marzo 2011, Rec. 4850/2007; de 7 de noviembre 2011, Rec. 6077/2009 o de 29 de abril 2011, Rec. 1261/2008.

${ }^{31}$ SSTS de 28 de noviembre 2011, Rec. 760/2010; de 29 de marzo 2011, Rec. 5050/2007 y de 14 de noviembre 2011, Rec. $6642 / 2009$

32 Puede verse en las SSTS de 22 de septiembre 2008, Rec. 1848/2004; de 2 de octubre 2009, Rec. 3607/2006, de 18 de diciembre 2009, Rec. 3630/2006 o de 29 de octubre 2010, Rec. 589/2007. 
19. Como podemos apreciar, los antecedentes penales y policiales -independientemente de que al iniciarse el expediente estén o no cancelados- pueden servir de elemento indiciario, de "indicador cualificado de la conducta de un ciudadano, sin que puedan ser, por sí solos, un obstáculo para la concesión de la nacionalidad española si queda suficientemente demostrado por las demás pruebas practicadas que el solicitante observa una buena conducta civica"33. Pero en ningún caso deberán hacer prueba plena de la ausencia de buena conducta.

20. De esta forma, el haber sido condenado penalmente no arrastra necesariamente la conclusión de mala conducta cívica, de igual manera que la buena conducta no queda acreditada por la ausencia de antecedentes penales. Todos los elementos que puedan ser recabados para crear en la autoridad judicial una convicción deberán ser tenidos en cuenta y sólo la valoración de su conjunto permitirá una resolución acorde a derecho. El concepto de civismo se nos presenta entonces como un requisito adicional a la no transgresión de las normas ${ }^{34}$ ya que no sólo se trata de no haber delinquido sino de respetar las pautas de conducta de la sociedad en que el sujeto se inserta ${ }^{35}$.

Todo ello ha hecho que nuestros Tribunales relativicen la importancia de los antecedentes penales: aun habiendo sido cancelados, la conducta incívica del extranjero puede ser evidente y, por el contrario, el civismo del solicitante puede resultar tal que sea irrelevante la existencia de antecedentes penales sin cancelar. De hecho, ha podido comprobarse en numerosas ocasiones como el tener antecedentes penales no suponía la denegación de nacionalidad si aquellos no eran el resultado de infracciones penales graves ${ }^{36} \mathrm{o}$ de conductas reiteradas o si había transcurrido un lapso de tiempo razonablemente dilatado entre la comisión del hecho delictivo y la solicitud de nacionalidad ${ }^{37}$, o si el proceso penal por delito finalizó con la absolución del sujeto ${ }^{38}$, los antecedentes penales se cancelaron antes de tramitar la solicitud de nacionalidad ${ }^{39}$, o se produjo el sobreseimiento ${ }^{40}$.

\footnotetext{
${ }^{33}$ Fundamento Jurídico $2^{\circ}$ de la SAN 1191/2020, Sec. $3^{\text {a }}$, de 10 de junio 2020. ECLI: ES:AN: 2020:1191

${ }^{34}$ SSTS de 17 de marzo 2009, Rec. 8559/04 y de 26 de mayo 2009, Rec. 1970/05.

${ }^{35}$ STS de 18 de junio 2009, Rec. 2915/05.

${ }^{36}$ Resulta indicativa de dicha tendencia jurisprudencial la STS, Sec. 6 , de 29 de abril 2011, Rec. 367/2008: “(...) aun cuando la condena penal impuesta a la solicitante constituía un inicial obstáculo para la apreciación de esa buena conducta cívica, ese obstáculo puede entenderse superado por la escasa entidad de los hechos imputados y por la propia levedad de la condena impuesta (dos días de arresto por cada una de las dos faltas por las que se le condenó), así como por la distancia temporal entre aquellos hechos y la fecha en que se solicitó la nacionalidad española, más aún si se tiene en cuenta que no constan ni se han invocado por la Administración cualesquiera otros datos desfavorables en su contra (...)"

${ }^{37}$ STS, Sec. 6 a, Rec. 5580/2005, de 26 mayo 2009.

STS, Sec. 6a, de 4 de abril 2011, Rec. 5868/2007: “ (...) aun cuando la condena penal impuesta en su día al interesado constituía un inicial obstáculo para la apreciación de esa buena conducta cívica, ese obstáculo puede entenderse superado por datos positivos suficientemente acreditados, como el carácter puntual y aislado del delito cometido, la no reiteración de conductas infractoras, la lejanía de aquellos hechos y la cancelación de los antecedentes penales correspondientes, así como su prolongada, plena y pacifica integración familiar y social en España".

Más claramente, la STS de 25 de febrero 2011, Rec. 2911/2007, cuando indica que “(...) conviene tomar en consideración la conducta del solicitante durante un periodo de tiempo significativo, con ello la proximidad o lejanía temporal en la realización de conductas que pudieran poner en cuestión la buena conducta civica, y ponderar los factores positivos que muestren un comportamiento civico conforme con los valores sociales y deberes razonablemente exigibles...".

${ }^{38}$ STS de 12 diciembre 2011, Sec. $6^{\text {a }}$, Rec. 1801/2010.

${ }^{39}$ STS de 27 octubre 2010, Sec. $5^{\text {a }}$, Rec. 4307/2006.

${ }^{40}$ STS de 28 septiembre 2005, Sec. $6^{\text {a }}$, Rec. 4919/2001. El Tribunal, en su Fundamento Jurídico $4^{\circ}$ dice: “(...) que está suficientemente probado que si bien el recurrente cometió en 1990 dos hechos delictivos por los que fue condenado, a partir de ese mismo año su conducta carece de reproche alguno, y, por el contrario, muestra un comportamiento que es el que exige la sociedad como representativo de un ciudadano estándar en tanto que posee una vida familiar estable, tiene un trabajo con el que atiende a las necesidades familiares, goza de un domicilio familiar conocido, paga sus impuestos y tiene buena fama cívica y religiosa en su entorno según expresa el documento al que antes nos referimos. Es decir, desde hace más de quince años al hoy recurrente no cabe hacerle reproche alguno, en lo que hace a su conducta social y cívica y por tanto está suficientemente justificada una rehabilitación total del mismo no pudiendo constituir sus errores de un pasado lejano en el tiempo, estigma insubsanable cuando se ha acreditado en la forma en que acontece en el caso de autos como absoluta su integración cívica y social y una conducta acorde a esa integración durante tan largo periodo de tiempo".
} 
21. Siguiendo la actual tendencia que aboga por la flexibilidad en la valoración, el Tribunal Supremo ${ }^{41}$ ha considerado determinantes de una buena conducta cívica circunstancias ajenas a los antecedentes penales y policiales, prestando atención a comportamientos concretos como el conocimiento de la lengua, la actividad laboral prolongada, las cotizaciones a la Seguridad Social, la implicación en actividades vecinales, la presentación regular de las declaraciones de la renta..., de forma que, en ocasiones, determinados antecedentes penales en vigor no permiten formular un juicio negativo sobre el comportamiento cívico del sujeto si median algunas de esas conductas ${ }^{42}$.

22. Pese a lo anterior, ello no impide que siga habiendo resoluciones que deniegan la nacionalidad al extranjero con antecedentes penales, aunque el delito no sea significativo en sí mismo ${ }^{43}$, hayan caducado sus antecedentes penales y sea manifiesta su integración personal, laboral y familiar ${ }^{44}$. En tales casos sería, por tanto, necesario, no sólo acreditar que nunca se han tenido antecedentes penales ni policiales, sino también, una conducta cívica intachable. Estaríamos, en consecuencia, ante dos requisitos que habrían de presentarse de forma acumulada ${ }^{45}$, no ante la condición exigida por el art. $22 \mathrm{CC}$ y sujeta a interpretación. Así se puso ya de relieve en la Sentencia del Tribunal Supremo, de 22 de noviembre de 2001 (Rec. casación núm. 7947/1997) ${ }^{46}$ y en otras más recientes que siguen su mismo rígido hilo conductor, exigiendo no solo verificar la ausencia de antecedentes sino también la trayectoria personal del solicitante, su exteriorización del civismo, el respeto a unas pautas de comportamiento en sociedad y cualquier tipo de "dato útil" que permita encajar su conducta en la de un buen ciudadano ${ }^{47}$.

\footnotetext{
${ }^{41}$ STS, Sec. $5^{\text {a }}$ de 27 de octubre 2016, Rec. 1179/2016.

${ }^{42}$ STS, Sec. $6^{\text {a }}$, de 2 de octubre 2015, Rec. 2767/2013.

${ }^{43}$ Fundamento Jurídico $4^{\circ}$, SAN 772/2020, Sec. $6^{\text {a }}$, de 6 de junio 2020. ECLI: ES:AN: 2020:772 “(...) por mucho que el hurto por el que fue condenado el actor fuera de escasa cuantía, la conducta desplegada por aquel se revela incompatible con los estándares mínimos de una buena conducta civica, sobre todo habida cuenta de la coincidencia de dichos hechos con la solicitud de nacionalidad española.
}

${ }^{44}$ Así puede constatarse en la STS, Sec. $6^{\text {a }}$ de 12 de noviembre 2007, que deniega la nacionalidad ante una detención policial por delito de falsificación de documento. Y ello, cuando las actuaciones fueron sobreseídas, los antecedentes, cancelados y constaba, asimismo, un Informe del Encargado del Registro Civil alegando la buena conducta cívica del solicitante.

${ }^{45}$ STS de 15 de diciembre de 2004, Rec. 1876/2001 “(...) El artículo 22 del Código Civil establece como uno de esos requisitos que el solicitante acredite positivamente la observancia de buena conducta cívica, es decir, no basta que no exista constancia en los registros públicos de actividades merecedoras de consecuencias sancionadoras penales o administrativas que "per se" impliquen mala conducta, lo que el art. 22 del Código Civil exige es que el solicitante justifique positivamente que su conducta, durante el tiempo de residencia en España y aun antes, ha sido conforme a las normas de convivencia cívica, no sólo no infringiendo las prohibiciones impuestas por el ordenamiento jurídico penal o administrativo, sino cumpliendo los deberes civicos razonablemente exigibles, sin que la no existencia de antecedentes penales sea elemento suficiente para entender justificada la buena conducta civica, tal y como establece la sentencia del Tribunal Constitucional 114/87 (...).”. Y sigue: “(...) en la sentencia de 16 de Marzo de 1.999 se decía que en el supuesto de la concesión de nacionalidad por residencia, la exigencia de "justificar, en el expediente regulado por la legislación del Registro Civil, buena conducta cívica" (además de suficiente grado de integración en la sociedad española) (artículo 22.4 del Código Civil), constituye un requisito adicional sobre la mera observancia de una conducta de no transgresión de las normas penales o administrativas sancionadoras, impuesto por el ordenamiento jurídico en razón del carácter excepcional que supone el reconocimiento de la nacionalidad por residencia y, por ende envuelve aspectos que trascienden los de orden penal y ha de ser valorada atendiendo a la conducta del solicitante durante un largo periodo de tiempo de permanencia en España y no puede identificarse sin más con la ausencia de antecedentes penales o policiales..."

${ }^{46}$ Se alude a ella en la SAN 1191/2020, Sec. $3^{\text {a }}$, de 10 de junio 2020, ECLI: ES:AN: 2020:1191. También, en STS de 25 de febrero 2011, Rec. 2911/2007: “ (...) Nada tiene que ver pues el concepto jurídico indeterminado "buena conducta civica” a que se refiere el artículo 22.4 del Código Civil, con la carencia de antecedentes penales, ya que la "buena conducta cívica" (además de suficiente grado de integración en la sociedad española) (artículo 22.4 del Código Civil), constituye un requisito adicional sobre la mera observancia de una conducta de no transgresión de las normas penales o administrativas sancionadoras, impuesto por el ordenamiento jurídico en razón del carácter excepcional que supone el reconocimiento de la nacionalidad por residencia y, por ende envuelve aspectos que trascienden los de orden penal y ha de ser valorada atendiendo a la conducta del solicitante durante un largo periodo de tiempo de permanencia en España y no puede identificarse sin más con la ausencia de antecedentes penales o policiales..."

${ }^{47}$ SSTS de 11 abril 2011, Sec. 6a , Rec. 6311/2007; y 29 marzo 2011, Rec. 603/2007.

Esta doctrina también se lee, entre otras, en las SSTS de 28 de noviembre 2011, Rec. 772/2010 y en las de 19 de diciembre 2011, Rec. 759/2010 y 3146/2010: "El cumplimiento de tal requisito viene determinado, por lo tanto, no solo por la ausencia de elementos negativos en la conducta del solicitante, como pueden ser transgresiones de las obligaciones de distinta naturaleza que el ordenamiento jurídico impone al ciudadano, sino por la acreditación positiva de un comportamiento conforme con los principios y valores cívicos de la comunidad en la que se integra, que ha de resultar más expresiva, convincente y concluyente 
23. Ahora bien, si de los antecedentes penales vigentes se pueden concluir que ni siquiera ellos son elemento decisivo para la denegación si, a su lado concurren comportamientos reiterados y duraderos de un conducta cívica intachable; y que el reproche social y la alarma ante una potencial peligrosidad han de ceder ante los principios de reeducación y reinserción social que recoge la Constitución (art.25,2), resulta una contradicción evidente propugnar la reinserción como valor y, acto seguido, denegar el derecho a obtener la nacionalidad en virtud de una condena (con independencia de consideraciones como la gravedad o levedad de la conducta o su carácter puntual o reiterado).

24. En la Sentencia de referencia, la Comisaría Local de la Policía Nacional en Ibiza, lugar de residencia del peticionario, dictó Auto firme de sobreseimiento libre parcial, por delitos de atentado a agente de la autoridad, estafa y lesiones. Asimismo, los antecedentes policiales fueron cancelados, lo que a juicio de nuestro TS supone que, tras eliminarse todos los efectos de la conducta reprochable, ésta ha desaparecido del mundo jurídico ${ }^{48}$. Ello abunda en el criterio del alto Tribunal cuando reitera la idea de que hay que analizar la trayectoria vital del solicitante de nacionalidad desde una perspectiva integral, conjunta, sin parcelar ${ }^{49}$ valorando su comportamiento con arreglo a la conducta estándar de un ciudadano medio.

\section{Conclusiones}

25. Como viene indicando la jurisprudencia más reciente, la buena conducta cívica es un requisito insoslayable para la concesión de la nacionalidad española, aunque su apreciación por el órgano con competencia exija un examen completo de la trayectoria personal del solicitante, que debe ir más allá de la mera comprobación de la existencia de antecedentes penales o policiales ${ }^{50}$.

26. Concluir -como se hizo por las Resoluciones de la DGRN y la SAN- que no ha podido acreditarse buena conducta por no haber aportado el requisito documental de la ausencia de antecedentes penales, es resolver el expediente de forma simplista. La base exclusiva de una reseña policial o un antecedente penal -o su falta de presentación- ha de ser enmarcada dentro de la trayectoria personal, social y vital del solicitante ${ }^{51}$. La prueba indiciaria que representa el antecedente penal (o su ausencia de presentación) es tan sólo eso, una mera señal, un elemento más a considerar de entre los muchos y variados que proporciona a la autoridad la presencia de un concepto jurídico sin determinación legal.

27. Ante esta exigencia tradicional de acumulación de requisitos deberíamos estar en condiciones de defender que la existencia o inexistencia de antecedentes penales y/o policiales, siendo condiciones importantes en la tramitación formal del expediente, no deberían adquirir la categoría de elemento

cuando median situaciones y actuaciones que, al margen de la trascendencia penal, merecen una valoración negativa a efectos de cumplir con tal requisito de buena conducta cívica."

${ }^{48}$ Respecto a la cancelación de antecedentes penales se manifestó la STC 174/1996, considerando que "... prolongar los efectos de los antecedentes penales más allá de su cancelación choca con el art. 25 de la Constitución y con la finalidad trascendente de reinserción social de las penas".

49 "El concepto jurídico indeterminado "buena conducta cívica" debe ser valorado por la Administración y, en su caso, por el órgano jurisdiccional que conozca de la materia en vía de recurso contencioso, como un requisito exigible para la concesión de la nacionalidad española que debe ser apreciado mediante el examen de la trayectoria personal del demandante de la nacionalidad, considerando aquélla en su conjunto y en modo alguno en relación a un periodo de tiempo predeterminado". Así se expresa la STS de 15 de diciembre 2004, Rec. 1876/2001 ya citada. En este sentido, se pronuncian también sendas SSTS de 10 de octubre 2011, Rec. 2568/2009 y 1500/2009 y de 14 de enero 2011, Rec.4556/2007, entre otras.

Asimismo, la SAN, Sec. $3^{\text {a }}$, 1108/2020, de 8 de junio 2020. ECLI: ES:AN: 2020:1108. “ (...) Por lo expuesto es preciso valorar la trayectoria personal del solicitante en su conjunto (v. gr. contenido del comportamiento que se reputa de incivico, afectación a los valores sociales y convivenciales, habitualidad y mantenimiento en el tiempo, distancia temporal con la solicitud, elementos positivos que pudieran contrarrestar los aspectos negativos etc.) sobre la base de un estándar medio de conducta capaz de ser asumido por cualquier cultura y por cualquier individuo, un estándar que vale para todos y vale para cada uno".

${ }^{50}$ SAN 383/2020, Sec. $3^{\text {a }}$, de 3 de febrero 2020 - ECLI: ES:AN:2020:383.

${ }^{51}$ SAN, Sec. $3^{\text {a }}$, de 20 de noviembre 2014, Rec. 939/2013. 
decisivo. En numerosas sentencias aludidas en este trabajo seguimos viendo que la carga de probar la buena conducta cívica exige al solicitante de nacionalidad acreditar no sólo la ausencia de sanciones penales o administrativas plasmadas en registros públicos sino, además, que su conducta ha sido conforme a las pautas de convivencia cívica; es decir, se trata de no infringir la normativa penal y administrativa $\mathrm{y}$, además, de actuar con civismo en todas las facetas de la vida ordinaria. Y una vez que el solicitante ha cumplido con la carga de probar, el juez debe verificar -a la vista de lo aportado- si, efectivamente, existe esa buena conducta cívica que conduciría a la concesión de la nacionalidad por residencia. Como dice la reciente jurisprudencia, al solicitante se le impone esta exigencia específica como consecuencia del "plus" que conlleva el acto de otorgamiento de la nacionalidad; y esa acreditación positiva ha de ser más convincente y concluyente si, como en este caso, la aportación del requisito documental no ha podido llevarse a cabo.

28. Pues bien, en la resolución del TS que justifica estas páginas, hemos comprobado la incidencia que tiene en la concesión de la nacionalidad española por residencia la ausencia de aportación de documentos requeridos -así como el peso de los antecedentes penales- y si ello es elemento decisivo para denegar la nacionalidad por no quedar suficientemente probada la buena conducta cívica. Encadenar la falta de entrega de cierta documentación a las dificultades para que la autoridad competente pueda tener certeza bastante de la buena conducta cívica que la normativa exige, es un desacertado silogismo del que el TS se aparta en la Sentencia analizada.

La importancia de la resolución es ciertamente notable, ya que se plantea con claridad, que no resulta admisible considerar la aportación documental, en este caso los antecedentes -penales o policiales- cancelados, como un obstáculo insalvable en la obtención de la nacionalidad siendo, como es, un requisito reglamentario sin apoyo en normas con rango de Ley, circunstancia que avala la legitimidad de un menor alcance en lo relativo a su exigibilidad.

Además, la falta de acreditación documental tiene, en el caso Messaoud, una connotación compleja basada en las dificultades insoslayables que el solicitante alegó para obtener los documentos requeridos. La no aportación debida a las razones políticas que provocaron la huida del país del militar argelino ha sido debidamente complementada con otras pruebas que, de manera indubitada, ponen de manifiesto para el TS la buena conducta cívica del solicitante. De todo ello puede deducirse el cumplimiento de sus deberes cívicos durante el tiempo de residencia en España bajo parámetros razonablemente exigibles para poder acceder a la concesión de la nacionalidad española por residencia ${ }^{52}$.

29. Así, como indica el alto Tribunal, aunque pese sobre el solicitante la carga de la prueba de su observancia de buena conducta cívica, será el juez quien deba valorarla apreciándola en su conjunto ${ }^{53}$, ponderando con flexibilidad las circunstancias concurrentes y eludiendo considerar las exigencias reglamentarias de documentación como elemento insalvable para proceder a la concesión de la nacionalidad. Y, como sigue apuntando, esta indispensable ponderación y una "más intensa proactividad de la Administración en la tramitación procedimental" (apdo. 3 del Fundamento Jurídico $5^{\circ}$ ) que recae en la apreciación de los requisitos, entendemos que habrá de proyectarse sobre futuros litigios en el ámbito del Derecho de Extranjería ${ }^{54}$.

\footnotetext{
${ }^{52}$ A.L. Calvo Caravaca; J. Carrascosa González; A. Durán Ayago; B. Carrillo Carrillo, Curso de nacionalidad y extranjería, Colex, Madrid, 2017.

${ }^{53}$ STS de 15 de diciembre 2004, Rec.1876/2001.

${ }^{54}$ M. Vargas Gómez-Urrutia, "Una lectura crítica de los vínculos familiares a la luz de la Directiva 2003/86/CE y de las normas españolas de extranjería”, en Cuadernos de Derecho Transnacional (octubre 2018), Vol. 10, nº 2.
} 